\title{
Consciousness, Religiosity and Locus of Control as Predictors of Well-Being among Young Adolescents
}

\author{
Shaktiyanshi Raundeley ${ }^{1 *}$, Dr. Preet Kumari ${ }^{2}$
}

\section{ABSTRACT}

The main aim of present study was to examine the relationships between well-being, Religiosity, A study was made on convenient sample of 50 young adolescents (females) age range of 18 to 22 years and used 4 tools (i) Well-being scale (Edinburgh, 2006) (ii) Religiosity scale (Bhusan,1970) (iii) Consciousness scale (Brazdau,2009) (iv)Locus of control scale (Rotter,1966). Co relational design was used. Results indicate that Well-being and Religious scores are positively correlated $(\mathrm{r}=0.31, \mathrm{p}<0.05)$. There is also high positive co relational between well-being and consciousness scores $(\mathrm{r}=0.42, \mathrm{p}<0.01)$. Thus increases in consciousness and religious scores led to increase in well=being scores among young adolescents. Multiple regression analysis was also used $(\mathrm{R}=0.46)$ and it showed that Consciousness has highest contribution in determination of criterion variable i.e. well-being, the regression coefficient being 0.15 . Religiosity has less contribution and locus of control has negligible contribution, the regression coefficient being 0.05 and 0.003 respectively.

Keywords: Consciousness, Religiosity, Locus of control

Adolescence is a period of transition between childhood and adulthood and is highly related with biological, physical, emotional, cognitive, social and psychological, changes (Kaplan, 2004). Well-being as a construct in recent times has sanctioned a flourishing place in the field of psychology and social sciences (e.g. Huppert, 2005; Layard, 2005; Marks \& Shah, 2005; Marmot, Ryff, Bumpass, Shipley, \& Marks, 1997; Mulgan, 2006). Positive mental health is defined as "a state of well-being in which the individual realizes his or her own abilities, can cope with the normal stresses of life, can work productively and fruitfully, and is able to make a contribution to his or her community”.

Consciousness lies at the root of all knowledge. It exists, but to identify it is like trying to locate the sun through dark clouds. It may be defined as a subjective awareness of some aspects of

\footnotetext{
${ }^{1}$ Research Scholar, Department of Psychology, Dayalbagh Educational Institute, Agra, India

2 Assistant Professor, Department of Psychology, Dayalbagh Educational Institute, Agra, India

*Responding Author

(C) 2016 S Raundeley, P Kumari; licensee IJIP. This is an Open Access Research distributed under the terms of the Creative Commons Attribution License (http://creativecommons.org/licenses/by/2.0), which permits unrestricted use, distribution, and reproduction in any Medium, provided the original work is properly cited.
} 
ongoing mental (psychical) processes. Consciousness is an individual's perception of his own internal mental state, a private universe of his own. Religion is an important context for development because it provides a means of socialization in areas such as moral behavior and offers emotional support to individuals from the cradle to the grave. (Hood et.al., 2003 and Roof, 1999). There is also support for the idea that religiosity fosters a more positive internal state (e.g., self-esteem) and protects against negative internalized outcomes (e.g., depression) in adolescents. Positive associations have also been found between personal prayer and self-esteem (Maltby et. al., 1999) and between overall religiosity and self-esteem (Ball et. al.,2003). Locus of control is defined as an individual's generalized expectancies regarding the forces that determine rewards and punishments. Individuals with an internal locus of control view events as resulting from their own actions. Persons with an external locus of control view events as being under the control of external factors such as luck (Marsh \& Weary, 1995).

In this study, three variables consciousness, locus of control and religiosity have been studied to see their contribution in wellbeing. Locus of control is a concept that has a significant effect on our daily lives. The way individuals interpret such events has a profound effect on their psychological well-being. Research has shown that there is much support for the relationship between religiosity and psychological well-being.

\section{Problem}

The aim of present study was to examine the relationships between well-being, Religiosity, Consciousness and locus of control among young adolescents.

\section{Objectives}

1. To study the relationship between well-being and religiosity among adolescents.

2. To study the relationship between well-being and consciousness among adolescents.

3. To study the relationship between well-being and locus of control among adolescents.

4. To study the relationship between religiosity and consciousness among adolescents.

5. To study the relationship between religiosity and locus of control among adolescents.

6. To study the relationship between consciousness and locus of control among adolescents

\section{Hypotheses}

1. There is no significant relationship between wellbeing and religiosity of adolescents.

2. There is no significant relationship between wellbeing and consciousness of adolescents.

3. There is no significant relationship between wellbeing and locus of control of adolescents.

4. There is no significant relationship between religiosity and consciousness of adolescents.

5. There is no significant relationship between religiosity and locus of control of adolescents.

6. Relative contribution of consciousness would be most remarkable as compared to religiosity and locus of control towards well-being. 


\section{Sample}

A convenient sample of 50 adolescents (females) pursuing their graduation courses was selected from D.E.I., Agra. They had sound understanding of Hindi and English language. Their age ranged from 18 to 22 years.

\section{Research Tools}

\section{Well-being Scale}

Well-being scale was developed by Edinburgh (2006). The scale consisted of 14 items. This scale aims to capture a wide conception of well-being, including affective-emotional aspects, cognitive-evaluative dimensions and psychological functioning. It is a Likert type scale. The score for each item range from 1 to 5 respectively, giving a minimum score of 14 and maximum score of 70. A higher WEMWBS score therefore indicates a higher level of mental well-being. Internal consistency estimates of less than 0.70 were sought. Test-retest reliability was 0.83 ( $\mathrm{p}<$ $0.01)$.

\section{Religiosity Scale}

This scale was developed by Bhusan (1970). The final form of this test contained only 36 items, out of which 25 were positive and 11 negative items. It was verified that they covered all the important dimensions of religiosity. R-scale is a five point Likert type scale. As the number of items in the scale is 36 , the range of possible scores on it is from 36 to 180, higher score indicating greater degree of religiosity. Bhusan reported split-half reliability as 0.82 and testretest reliability as 0.78 . The scale possesses content validity and predictive validity.

\section{Consciousness Quotient Inventory(CQ-i)}

Brazdau (2009) developed the Consciousness Quotient Inventory. CQ-i is a psychological inventory that measures the conscious experience on six dimensions: physical, emotional, cognitive, spiritual, and social and self-consciousness. CQ-i contains 61 items, scored using a Likert scale. Psychometric properties of validity and reliability have been shown to be quite high in academic samples.

\section{Rotter's Locus of Control Scale (I- E Scale)}

The Locus of Control Scale was developed by Rotter (1966).The scale is a forced choice instrument which consists of 29 pairs of statements, 23 of which are scored and 6 filler items (not to be scored) from different life situations, where locus of control attitudes might be relevant to behavior. A high score indicates a belief in an external locus of control on the internal-external dimension of score. In addition, reliability figures (estimated by split half) is 0.88 and (estimated by test- retest) is 0.85 of its Hindi version. 


\section{Design}

To study the relationship between wellbeing, religiosity, consciousness and locus of control among adolescence co-relational design was be used.

\section{Variables}

Predictor Variables:

- Religiosity

- $\quad$ Consciousness

- Locus of control

\section{Criterion Variable:}

- Well-being

\section{Control Variables:}

- $\quad$ Age - students belonging to age range of 18-22 years

- $\quad$ Educational qualification- graduation

- $\quad$ Gender - female

\section{RESULTS AND DISCUSSIONS}

For the statistical analysis of the obtained raw scores, the product moment coefficients of correlation were computed to test the proposed hypotheses. Correlation matrix (Table-1) was formed which shows inter-correlations among proposed variables.

Table-1 Correlation Matrix

\begin{tabular}{|l|l|l|l|l|l|l|}
\hline & Mean & SD & Religiosity & Cons. & LOC & Wellbeing \\
\hline Religiosity & 134.9 & 14.7 & 1 & & & \\
\hline Cons. & 191.34 & 37.9 & 0.31 & 1 & & \\
\hline LOC & 8.82 & 3.2 & -0.11 & 0.12 & 1 & \\
\hline Wellbeing & 48.68 & 7.5 & $0.31^{*}$ & $0.42^{* *}$ & -0.008 & 1 \\
\hline
\end{tabular}

${ }^{* *} \mathrm{p}<0.01 \quad{ }^{*} \mathrm{p}<0.05$

Table-1 presents the coefficient correlation between Religiosity, Consciousness Locus of control and Well-being. It is evident from the table that well-being and religiosity scores are positively correlated $(\mathrm{r}=0.31, \mathrm{p}<0.05)$. Thus increases in religiosity scores led to increase well-being scores. There is high positive correlation between well-being and consciousness scores ( $\mathrm{r}=0.42$, $\mathrm{p}<0.01)$.Thus increases in consciousness scores led to increase in well-being scores among adolescents. To sum up it may be inferred that well-being is positively related with both factors i.e. consciousness and religiosity. Negligible correlation was found between locus of control and well-being ( $\mathrm{r}=-0.008)$ and Negative correlation was found between religiosity and locus of control $(r=-0.11)$. There is a positive correlation between religiosity and consciousness scores $(r$ $=0.31, \mathrm{p}<0.05$ ). Thus increases in religiosity scores led to increase in consciousness scores among adolescents. 
Consciousness, Religiosity and Locus of Control as Predictors of Well-Being among Young Adolescents

Table-2 Results Of Multiple Regression Analysis

\begin{tabular}{|l|l|}
\hline Multiple R & 0.46 \\
\hline R square & 0.22 \\
\hline Adjusted R Square & 0.16 \\
\hline Standard Error & 6.9 \\
\hline Observation & 50 \\
\hline
\end{tabular}

In the table the value of Adjusted $\mathrm{R}$ square was found to be 0.16 which indicates that $16 \%$ variance in wellbeing is to explained by the combined predictor variables.

Table: 3 Analysis Of Variance:

\begin{tabular}{|l|l|l|l|l|}
\hline ANOVA & df & SS & MS & F \\
\hline Regression & 3 & 606.196 & 202.065 & $4.216^{*}$ \\
Residual & 46 & 2204.683 & 47.92791 & \\
\hline
\end{tabular}

$* * \mathrm{p}<0.01$

Table:4 Multiple Regression Coefficients

\begin{tabular}{|l|l|l|l|l|l|l|}
\hline Variables & $\mathbf{B}$ & $\mathbf{S E}$ & $\boldsymbol{\beta}$ & $\mathbf{t}$ & $\mathbf{r}$ & $\begin{array}{l}\text { Coefficient of } \\
\text { Determination }\end{array}$ \\
\hline Religiosity & 0.096 & 0.07 & 0.17 & 1.36 & $0.31^{*}$ & 0.05 \\
\hline Consciousness & 0.074 & 0.03 & 0.35 & $2.66^{*}$ & $0.42^{* *}$ & 0.15 \\
\hline LOC & -0.092 & 0.32 & -0.04 & -0.29 & -0.008 & 0.0003 \\
\hline Constant & 22.24 & & & & & \\
\hline
\end{tabular}

${ }^{*} \mathrm{p}<0.05{ }^{* *} \mathrm{p}<0.01$

Multiple Regression Analysis showed that Consciousness has highest contribution in determination of criterion variable i.e. Wellbeing, the regression coefficient being 0.15 . Locus of control has least contribution in determining wellbeing.

\section{Regression Equation:}

$$
\begin{aligned}
\mathrm{Y} & =\mathrm{B}_{1} \mathrm{X}_{1}+\mathrm{B}_{2} \mathrm{X}_{2}+\mathrm{B}_{3} \mathrm{X}_{3}+\mathrm{C} \\
& =0.096(134.9)+0.074(191.34)+(-0.092)(8.82)+22.24 \\
& =12.95+14.15-0.81+22.24 \\
& =48.53
\end{aligned}
$$

The obtained multiple regression equation states that every unit increase in $\mathrm{R}\left(\mathrm{X}_{1}\right)$ and $\mathrm{C}\left(\mathrm{X}_{2}\right)$ led to an increase in well-being scores by their respective coefficients $(0.09$ and 0.07$)$ and every unit increase in $\operatorname{LOC}\left(\mathrm{X}_{3}\right)$ led to decrease in well-being scores by their respective coefficients $(-0.09)$ when 22.24 was the value of constant. 


\section{DISCUSSION}

The first hypothesis which stated that there is no significant relationship between wellbeing and religiosity of adolescents is rejected because significant positive correlation was found between these two variables $(\mathrm{r}=0.28, \mathrm{p}<0.05)$. as studies showed that religiosity protects against negative youth psychological outcomes such as depression. For example, perceived importance of religion (Sinha et. al., 2007), "relational spirituality” (Desrosiers and Miller, 2007), and "meaningfulness of religion” (Writh et. al., 1993) have all been linked to lower levels of youth depression.

The second hypothesis that stated there is no significant relationship between wellbeing and consciousness of students is also rejected as high positive correlation was found between wellbeing and consciousness of students $(r=0.44, p<0.01)$. As Kelley (2010) studied thought recognition and psychological well-being and found that Significant positive relationships between both measures of thought recognition and psychological wellbeing and, in the follow-up study, both measures of thought recognition and mindfulness.

Negligible correlation was also found between locus of control and well-being therefore the third hypothesis that there would be no significant relationship between wellbeing and locus of control of adolescents is accepted.

The fourth hypothesis that stated there is no significant relationship between religiosity and consciousness of students is also rejected because there is positive correlation between religiosity and consciousness scores $(\mathrm{r}=0.31, \mathrm{p}<0.05)$.

The fifth hypothesis that there is no significant relationship between religiosity and locus of control of adolescents is partially rejected as there negative low correlation was found between the two.

The sixth and the last hypothesis that relative contribution of consciousness would be most remarkable as compared to religiosity and locus of control towards well-being is also accepted because consciousness was highly contributed in increasing well-being.

\section{Acknowledgments}

The author appreciates all those who participated in the study and helped to facilitate the research process.

\section{Conflict of Interests}

The author declared no conflict of interests.

\section{REFERENCES}

Ball. J., Armistead. L. and Austin. B.J. (2003). The relationship between religiosity and adjustment among African-American, female, urban adolescents. Journal of Adolescence, 26, (4), 431-446. 
Bhusan, L.I. (1970). Religiosity Scale. Agra: National Psychological Corporation.

Brazdau, O. (2009). The Consciousness Quotient (CQ) \& The CQ Inventory - Theory and Research: New York: Ny 10003, USA.

Desrosiers and Miller. L. (2007). Relational spirituality and depression in adolescent girls. Journal of Clinical Psychology, 63,(10) 1021-1037.

Edinburgh, W. (2006). Warwick Medical School, University of Warwick, Coventry, UK

Hood J. et. al. (2003). The Psychology of Religion: An Empirical Approach, Guilford Press, New York, NY, USA, 3rd edition.

Huppert, F.A. (2005). Positive mental health in individuals and populations. In F.A.Huppert, N.Baylis, \& B.Keverne (Eds.), The science of well-being, 307-340, Oxford: Oxford University Press.

Kaplan, P. S. (2004). Adolescence. Boston: Houghton Mifflin Company.

Layard, R. (2005). Happiness: Lessons from a New Science. New York: Penguin.

Maltby. J., Lewis. C.A. and Day. L. (1999). Religious orientation and psychological well-being: the role of the frequency of personal prayer. British Journal of Health Psychology, 4, 4, 363-378.

Marks, N. and Shah, H. (2005). A well-being manifesto for a flourishing society.In F.A. Huppert, N. Baylis and B. Keverne (Eds). The Science of Well-being, 503-533. Oxford: Oxford University Press.

Marmot, M. et. al., (1997). Social inequalities in health: next questions and converging evidence. Social Science and Medicine, 44, 901-910.

Mulgan, G. ( 2006). Good and bad power, the ideals and betrayals of government. London: Allen Lane.

Roof. W.C. (1999). Spiritual Marketplace: Baby Boomers and the Remaking of American Religion, Princeton University Press, Princeton, NJ, USA.

Rotter, J.B. (1966). Generalized expectancies for internal versus external control of

reinforcement. Psychological Monographs, 80(1), 171-214.

Sinha. J. W., Cnaan. R.A. and Gelles. R.J. (2007). Adolescent risk behaviors and religion: findings from a national study. Journal of Adolescence, 30, 2, 231-249.

Wright.L.S., Frost. C.J. and Wisecarver. S.J. (1993). Church attendance, meaningfulness of religion, and depressive symptomatology among adolescents. Journal of Youth and Adolescence, 22, 5, 559-568.

How to cite this article: S Raundeley, P Kumari (2016), Consciousness, Religiosity and Locus of Control as Predictors of Well-Being among Young Adolescents, International Journal of Indian Psychology, Volume 3, Issue 4, No. 77, ISSN:2348-5396 (e), ISSN:2349-3429 (p), DIP:18.01.069/20160304, ISBN: 978-1-365-51571-2 